\title{
A política habitacional brasileira e a habitação rural: um estudo preliminar sobre Santa Cruz do Sul, RS - Brasil
}

\author{
Brazilian housing policy and the rural housing: a preliminary \\ study about Santa Cruz do Sul, RS - Brazil
}

\section{Gabriel Anibal Santos de Oliveira Erica Karnopp}

Universidade de Santa Cruz do Sul - UNISC - Santa Cruz do Sul - Rio Grande do Sul - Brasil

\begin{abstract}
Resumo: Este artigo consiste em analisar a política habitacional brasileira e a habitação rural no município de Santa Cruz do Sul/RS - Brasil, desde a criação do Banco Nacional da Habitação (BNH) ao Programa Minha Casa - Minha Vida (PMCMV), com destaque ao Programa Nacional de Habitação Rural (PNHR). A partir da década dos anos 2000, verifica-se a existência de ações mais efetivas quanto ao equacionamento do déficit habitacional do meio rural. Essas ações vêm sendo realizadas com a implementação do Programa Minha Casa - Minha Vida, que tem como parte integrante o Programa Nacional da Habitação Rural. Esse programa vem sendo implementado a partir de 2011. Conforme os agricultores, as diversas entidades e instituições ligadas ao setor rural, o PNHR vem possibilitando o acesso a uma moradia digna às famílias rurais, possibilitando, dessa forma, atingir uma melhor qualidade de vida.
\end{abstract}

Palavras-chave: Política habitacional. Habitação rural. Programa nacional de habitação rural.

Abstract: This article is to analyse housing brazilian policy and rural housing in Santa Cruz do Sul/RS-Brazil, since creation of BNH to Minha Casa-Minha Vida Program with emphasis on National Rural Housing Program (PNHR). From the decade of the 2000s, there is the existence of more effective actions about the solution to the housing shortage of rural areas. These actions have been carried out with the implementation of Minha Casa-Minha Vida Program, which has the National Rural Housing Program (PNHR) as an integral part. This program has being implented since 2011. According to farmers, the various entities and institutions related to rural sector, PNHR has allowed access to decent housing for rural families, enabling thereby achieving better quality of life.

Keywords: Housing policy. Rural housing. National Rural Housing Program. 


\section{Introdução}

No Brasil, a partir da segunda metade da década de 1950, em função das rápidas transformações econômicas oportunizadas pelo governo do Presidente Juscelino Kubitschek e o seu Programa de Metas, o fluxo de pessoas para as metrópoles e grandes cidades tornou-se intenso.

Conforme Santos (1994, p. 29), "Entre 1940 e 1980, dá-se verdadeira inversão ao lugar de residência da população brasileira." Ainda, de acordo com o autor, o índice de urbanização brasileira cresceu rapidamente: em 1940 a população urbana era de $26,35 \%$ e, em 1980, alcançou 68,86\%. Esse processo no Brasil, como nos demais países da América Latina, apresenta-se, de longa data, em um cenário de desigualdades socioeconômicas, onde estão presentes lado a lado a modernidade e a exclusão social.

Para equacionar a questão habitacional urbana e rural no país, foi criada a Fundação da Casa Popular, em 1946. No entanto, a política habitacional realizada por essa Fundação não atingiu os objetivos propostos e foi extinta em 1964. No mesmo ano, com o intuito de reduzir o déficit habitacional brasileiro, foi instituído o Sistema Financeiro da Habitação (SFH), tendo como principal agente político habitacional do país o Banco Nacional da Habitação (BNH). Essa instituição financeira foi extinta em 1986 e suas atribuições passaram a ser desempenhadas pela Caixa Econômica Federal e pelo Ministério do Desenvolvimento Urbano e Meio Ambiente. No período entre 1990 e 1994 foram suspensos os financiamentos habitacionais com recursos do Fundo de Garantia do Tempo de Serviço (FGTS) e, em 1997, foi criado o Sistema de Financiamento Imobiliário, com o objetivo de promover 0 financiamento imobiliário para a classe média brasileira.

A partir dos anos 2000, as políticas relativas à questão habitacional têm sido realizadas por intermédio do Programa Minha Casa - Minha Vida e seus subprogramas: o Programa Nacional de
Habitação Urbana (PNHU) e o Programa Nacional de Habitação Rural (PNHR).

O presente artigo apresenta o resultado de um estudo preliminar sobre a política habitacional brasileira e a habitação rural a partir da criação do Sistema Financeiro da Habitação, em 1964, e o Programa Minha Casa - Minha Vida (PMCMV) criado em 2009. Destaca-se, especialmente, em Santa Cruz do Sul, o Programa Nacional de Habitação Rural e o Programa Minha Casa - Minha Vida.

Para realizar esta pesquisa, considerou-se o território compreendido pelo município de Santa Cruz Sul. Os dados para a realização da pesquisa foram obtidos junto ao Sindicato dos Trabalhadores Rurais de Santa Cruz do Sul, Cooperativa da Habitação Camponesa Ltda./MPA, Prefeitura Municipal de Santa Cruz do Sul, Empresa de Assistência Técnica e Extensão Rural (Emater), Sindicato Rural de Santa Cruz do Sul, Banco do Brasil e Caixa Econômica Federal.

Apresenta-se, inicialmente, uma retrospectiva da política habitacional brasileira, desde a Fundação da Casa Popular, na década 1940, da criação do BNH, em 1964, até a implantação do PMCMV. Num segundo momento destaca-se, de maneira sintética, 0 Programa Nacional de Habitação Rural (PNHR). A seguir expõe-se o resultado de um estudo sobre a situação da habitação rural e a implementação do PNHR no município de Santa Cruz do Sul. Por fim, apresentam-se as considerações finais da pesquisa.

\section{Retrospectiva da política habitacional brasileira}

A Política Nacional da Habitação teve seu primeiro período representado pela Fundação da Casa Popular, sendo considerada a primeira instituição voltada para realizar uma política habitacional destinada à população de baixa renda. Desde sua criação, em 1946, até sua extinção em meados da década de 1960, pouco realizou para atingir seu objetivo principal, que era o de promover o acesso à moradia digna para a população de baixa renda. Com carência de recursos, originada pela falta 
de repasses regulares de dotações orçamentárias, tornou-se um balcão de clientelismo políticoeleitoreiro. Nesse período, deve-se destacar que a política habitacional restringiu-se a atender as demandas em habitação no meio urbano, não havendo uma preocupação em buscar equacionar as necessidades de habitação das famílias rurais, mesmo considerando-se que a maioria da população brasileira ainda era rural. De acordo com Souza (2009, p. 121), "A política habitacional, originalmente pensada como redistributiva, transformou-se em uma política limitada pela barganha político-eleitoreira."

A partir do início da década de 1960, após acelerado crescimento da economia, especialmente na segunda metade dos anos de 1950, apresentando um aumento contínuo da inflação, que onerava os salários da classe trabalhadora, mesmo com a elevação da produtividade, os problemas econômicos foram agravados com a renúncia do Presidente Jânio Quadros, em agosto de 1961. Conforme Singer (1977) as medidas de combate à inflação, tomadas a partir de 1963, ocasionaram a queda do nível de atividade produtiva nacional.

Tendo em vista as difíceis condições econômicas em que se encontrava o país na época, a situação política achava-se em posição delicada, culminando em um impasse político que ocasionou a queda do governo do Presidente João Goulart, em março de 1964. As Forças Armadas assumiram o poder, tendo como Presidente o Marechal Castelo Branco. A partir de então ocorreu uma forte concentração de poder exercido pelo governo central.

A política econômica do novo governo tinha como principais objetivos o combate à inflação e a mobilização de outras formas de obtenção de recursos. Para tal, foi realizada a reforma fiscal, que foi obstaculizada no período anterior a 1964, e posteriormente possibilitada pela concentração das decisões no poder central. Além disso, foram criados fundos parafiscais ${ }^{1}$ como o FGTS e o Programa de Integração Social (PIS), dentre outros mecanismos.

\footnotetext{
1 Fundos parafiscais são fundos que têm origem nas contribuições elencadas no art. 149 da Constituição Federal, que são denominadas também de contribuições parafiscais, constituem-se em importante fonte de poupança compulsória,
}

Foi a partir de 1964, que o Estado interveio na produção de unidades habitacionais em larga escala. Teve como grande meta o incentivo à economia. Assim, de acordo com Bulgarelli (1966, p. 25), isso ocorreu por intermédio "[...] de uma política agressiva de financiamentos para novas construções, como também removendo obstáculos e criando condições de reativação do setor privado."

Nesse período pós-1964, destacou-se, nesse setor da economia, a criação da Lei no 4.380, de 21 de agosto de 1964, do Sistema Financeiro da Habitação (SFH), que tinha como finalidade a captação de recursos para a área habitacional, bem como o financiamento, a aquisição e a construção da casa própria. Como principal agente de operação desse sistema foi criado, pela mesma lei, o $\mathrm{BNH}$. Essa instituição tinha a função de fiscalizar, regulamentar e prestar assistência aos demais agentes que faziam parte do sistema. As Caixas Econômicas, as Sociedades de Crédito Imobiliário e as Associações de Poupança e Empréstimo formavam os agentes de ponta do sistema, tendo em vista que o $\mathrm{BNH}$ funcionava como agente repassador dos recursos financeiros. As fontes de recursos para financiamento tinham origem nas cadernetas de poupança, nas letras imobiliárias e no FGTS. Também nesse período foi instituída a correção monetária. Essas medidas possibilitaram ao novo governo alcançar vários efeitos positivos de ordem econômica, tais como: estímulo à poupança, maior aproveitamento da mão de obra com menor qualificação, incentivo à indústria de material de construção, expansão e fortalecimento de empresas de construção, incorporadoras, escritórios de engenharia e arquitetura, imobiliárias, dentre outras.

Com a criação do Sistema Financeiro da Habitação, incluiu-se na legislação brasileira a questão da habitação rural. Por esse dispositivo, a

destinada às atividades de fomento como investimentos em áreas sociais, projetos de infraestrutura urbana, habitação,saneamento básico, agricultura familiar, dentre outras. Essas contribuições, que são de competência da União, caracterizam-se pela sua compulsoriedade, conjugadas com a sua destinação. Dividem-se em sociais (exemplos: PIS, PASEP, FAT, FGTS), econômicas (exemplo: Taxa de Melhoramento dos Portos) e profissionais, que são de interesse de categorias profissionais (exemplos: CREA, CRECI, OAB, CRC).(JARDIM, 1995). 
formulação da política nacional e de planejamento territorial estava afeta ao Ministério do Planejamento. Nesse sentido, a Lei 4.380/64 apresenta o seguinte teor:

Art. 1으 - O Governo Federal, através do Ministro de Planejamento, formulará a política nacional de habitação e de planejamento territorial, coordenando a ação dos órgãos públicos e orientando a iniciativa privada no sentido de estimular a construção de habitações de interesse social e o financiamento da aquisição da casa própria, especialmente pelas classes da população de menor renda.

Art. $4^{\circ}$ - Terão prioridade na aplicação dos recursos:

I - a construção de conjuntos habitacionais destinados à eliminação de favelas, mocambos e outras aglomerações em condições subumanas de habitação;

II - os projetos municipais ou estaduais que, com as ofertas de terrenos já urbanizados e dotados e dotados dos necessários melhoramentos, permitirem o início imediato da construção de habitações;

IV - a construção de moradia para a população rural. (BRASIL, LEI 4.380/64, DOUde 30.9.1964).

Com a instituição do SFH, o BNH tornou-se a primeira instituição que, até sua extinção, em 1986, pelo Decreto Lei oㅜ 2.291, de 21 de novembro, teve alcance nacional para instituir uma política habitacional. Mesmo com essa abrangência, a atuação dessa instituição ficou restrita ao atendimento das necessidades habitacionais do meio urbano.

O período entre 1968 e 1973, a partir das diretrizes do governo elaboradas em 1967, caracterizou-se como o de maior crescimento da história recente do Brasil. O crescimento do PIB atingiu taxa média superior a $10 \%$ a.a., destacandose o setor industrial. $O$ índice da inflação ficou entre $15 \%$ e $20 \%$. Dentre os principais fatores responsáveis por esse crescimento, segundo Gremaud et al. (2011) foram: os investimentos públicos em infraestrutura, a demanda por bens duráveis, investimento das empresas estatais, crescimento das exportações, dentre outros. Nesse conjunto de fatores, cabe destaque para a construção civil, que de acordo com Gremaud et al. (2011, p. 386) "[...] cresceu a uma taxa média de $15 \%$ a.a., por força do aumento dos investimentos públicos nessa área, e à maior demanda por habitações provocada pela expansão do crédito do SFH."

O BNH era o principal agente de transferência dos recursos públicos empregados pelo Estado ou a serem transferidos ao setor privado, na forma de crédito, para a realização da política governamental para o setor da construção civil. Assim, de acordo com Singer (1977, p. 112), "[...] o BNH oferecia crédito maciço aos construtores, permitindo-lhes acelerar as obras, e, desta maneira, encurtar o ciclo do capital e reduzir seus custos e ao mesmo tempo proporcionava aos adquirentes créditos de longo prazo, com o saldo reajustado trimestralmente de acordo com a inflação."

A partir da segunda metade da década de 1970, a economia do país começou a passar por sérias dificuldades, especialmente, em relação às altas taxas de inflação e com respeito à dívida externa. Nessa situação econômica desfavorável que acometeu o país, somada à mudança de rumo da aplicação de seus recursos para financiamento dos governos estaduais e municipais para a construção de grandes obras de infraestrutura urbana, o SFH entrou em crise. A esse respeito, Maricato (1987, p. 29-30) posiciona-se da seguinte maneira:

O sucesso do Sistema Financeiro da Habitação no Brasil desde a sua estruturação em bases mais exequíveis, em 1968, até 1980, quando entra em profunda crise em consonância com toda a economia do país, se deveu exatamente ao fato de ignorar os setores de menores rendimentos da população e tratar a habitação como uma mercadoria a ser produzida e comercializada em moldes estritamente capitalistas.

Esse período, que se prolongou até 1994, notabilizou-se pelo aprofundamento da crise na economia brasileira. Com vistas a controlar a difícil situação economia que perdurava, foram editados vários planos de estabilização econômica, com o objetivo principal de debelar os altos índices de inflação, especialmente a partir de segunda metade da década de $1980^{2}$.

\footnotetext{
2 Planos econômicos: Plano Cruzado, fevereiro de 1986; Plano Cruzado II, novembro de 1986; Plano Bresser, junho de 1987;
} 
Neste período destacaram-se o Plano Cruzado I, instituído pelo Decreto-Lei n 2.283, de 27 de fevereiro de 1986, com vigência a partir do dia 28 do mesmo mês, e o Cruzado II, instituído pelo DecretoLei no 2.290, de 21 de novembro de 1986, que vigorou até a implantação do Plano Bresser, em junho de 1987.

Dentre as diversas medidas contidas nesses planos, cabe destacar no Plano Cruzado I, no segmento habitacional, a extinção do BNH por intermédio do Decreto-Lei $n \cong$ 2.291, de 21 de novembro de 1986. As atribuições do BNH passaram a ser desempenhadas pela Caixa Econômica Federal e pelo Ministério do Desenvolvimento Urbano e Meio Ambiente - MDU. (DOU, 1986). Essa medida levou a desestruturação e a desarticulação do sistema, que persistiu até meados da década dos anos de 1990.

Tendo em vista que as medidas implementadas pelos planos acima citados já não mais atingiam os objetivos desejados, um novo plano econômico foi lançado em 12 de junho de 1987, o Plano Bresser. Sua vigência ocorreu entre 12 de junho de 1987 a 15 de janeiro de 1989.

Com a promulgação da Constituição Federal, em 5 de outubro de 1988, a questão da habitação rural foi inserida no art. 187, do capítulo III - Da Política Agrícola e Fundiária e da Reforma Agrária, da seguinte forma: (BRASIL, CONSTITUIÇÃO FEDERAL, 1988, p. 56).

Art. 187 - A política agrícola será planejada e executada na forma da lei, com a participação efetiva do setor de produção, envolvendo produtores e trabalhadores rurais, bem como os setores de comercialização, de armazenamento e de transportes, levando em conta, especialmente:

I - os instrumentos creditícios e fiscais;

II - os preços compatíveis com os custos de produção e a garantia de comercialização;

III - o incentivo à pesquisa e à tecnologia;

IV - a assistência técnica e extensão rural;

$\mathrm{V}$ - o seguro agrícola;

VI - o cooperativismo;

VII - a eletrificação rural e irrigação;

VIII - a habitação para o trabalhador rural.

Com a eleição de Presidente Fernando Collor de Mello, foi lançado por intermédio da Medida

Plano Verão, janeiro de 1989; Plano Collor, março de 1990; Plano Collor II, fevereiro de 1991; Plano Real, julho de 1994.
Provisória no 168, de 16 de março de 1990, e convertida na Lei no 8.024, de 12 de abril de 1990, o Plano Collor. Sua vigência foi de 16 de março de 1990 a 31 de julho de 1993, sendo divido em Plano Collor I e Plano Collor II.

O plano Collor iniciou a década dos anos de 1990 com a retenção dos recursos da poupança e de outros ativos financeiros, com o objetivo de reduzir a liquidez da economia, dentre outras medidas de ajuste. Essa medida afetou seriamente o setor da construção civil e o crédito imobiliário, pela diminuição do volume de financiamentos. Durante essa década os depósitos da poupança sofreram forte concorrência de outros ativos financeiros, diminuindo os recursos para o crédito imobiliário. Os financiamentos realizados por intermédio dos recursos do FGTS, também sofreram queda nesse período, tendo ficado suspensos no período de 1991 a 1994 qualquer tipo de empréstimo, por decisão do Conselho Curador do FGTS.

Durante o governo Collor foi aprovada a Política Agrícola, por intermédio da Lei n 8.171, de 17 de janeiro de 1991, que no seu Capítulo XX dispõe sobre a política de habitação rural nos seguintes artigos:

Art. 87. É criada a política de habitação rural, cabendo à União destinar recursos financeiros para a construção e/ou recuperação da habitação rural.

§ 10 Parcela dos depósitos da Caderneta de Poupança Rural será destinada ao financiamento da habitação rural.

Art. 88. Vetado

Art. 89. O poder público estabelecerá incentivos fiscais para a empresa rural ou para o produtor rural, nos casos em que sejam aplicados recursos próprios na habitação para o produtor rural. (BRASIL, LEI 8.171/91, DOU de 18.1.1991).

Com a situação política do país conturbada e lastreada pelos escândalos de corrupção ocorreu o impeachment do Presidente Fernando Collor de Melo. Assumiu a Presidência da República o vicepresidente Itamar Franco. Para ministro da fazenda foi nomeado Fernando Henrique Cardoso. Inicou-se, então, a criação de mais um plano econômico com vistas à estabilização econômica do país, o Plano 
Real, que foi implantado em 1994. O Plano Real foi o último plano de estabilização econômica adotado pelo Brasil.

Verifica-se que nesse período as principais ações destinadas à diminuição do déficit habitacional foram voltadas para o meio urbano. Como exemplo de ações nesse sentido, tem-se a criação do Sistema de Financiamento Imobiliário, em 1997, com a finalidade de promover o financiamento imobiliário para a classe média brasileira. Há poucos instrumentos legais que se referem ao atendimento das necessidades em moradias no meio rural. Dentre esses destacam-se as disposições constantes no capítulo III, da Constituição Federal de 1988 e no capítulo XX, da Lei $\mathrm{n}^{\circ}$ 8.171, de 17 de janeiro de 1991.

Com o objetivo de estabelecer diretrizes para uma Política Nacional de Habitação Rural, encontrase em tramitação no Congresso Nacional, desde 1990, o projeto de Lei no 6129-A/90.

Segundo Peres (2003), visando, também, atender as necessidades habitacionais no meio rural, foi apresentado pelo Deputado Francisco Graziano Neto, em novembro de 2000, um projeto de Lei Complementar nํ00167, denominado Novo Estatuto da Terra, que objetivava dispor sobre a política fundiária e agrícola e outras providências. Nesse projeto, arquivado em 2003, além da política fundiária e agrícola, incluía artigos versando sobre as condições de atendimento à população rural em suas necessidades relativas à moradia.

Mesmo com previsões legais e algumas iniciativas apresentadas, as políticas públicas voltadas para a questão habitacional rural não têm sido claras. Nesse sentido, Peres (2003, p. 78) afirma:

O papel do Estado, no Brasil, com relação a políticas públicas de habitação e desenvolvimento rural não tem sido claro, e menos ainda programas voltados à política de habitação rural. Os poucos programas de moradia existentes realizam-se desvinculados de uma estratégia nacional de desenvolvimento que inclua programas de geração de atividades produtivas e empregos permanentes. Além disso, existe uma falta de coordenação entre os escassos organismos que atuam na questão da habitação das áreas rurais, somada a um desconhecimento e uma desconsideração da legislação relativa a esse assunto.

Outros instrumentos de política habitacional foram criados, como o Estatuto da Cidade promulgado em 2001, o Programa de Arrendamento Residencial (PAR), com o objetivo de atender as necessidades habitacionais da população urbana de baixa renda e Ministério das Cidades, conforme a lei de $n^{\circ}$ 10.683, de 28 de maio de 2003. A partir de então esses instrumentos legais passaram a regular e o novo Ministério, o órgão responsável, pela política de desenvolvimento urbano, políticas setoriais da habitação, saneamento ambiental, transporte urbano e trânsito.

Em 2007, o Governo Federal criou o Programa de Aceleração do Crescimento com o objetivo de estimular o crescimento do Produto Interno Bruto e do emprego, de maneira a intensificar a inclusão social e melhorar a distribuição de renda. De acordo com o Ministério do Planejamento, o PAC 2007-2010 está organizado em cinco medidas: investimento em infraestrutura, estímulo a crédito e financiamento, melhora do ambiente de investimento, desoneração e aperfeiçoamento do sistema tributário, e medidas fiscais de longo prazo. ${ }^{3}$

Em 2008, foi aprovada a Lei no 11.888, de 24 de dezembro de 2008, que dispõe sobre a assistência técnica as famílias com renda mensal de até 3 (três) salários mínimos, residentes em áreas urbanas ou rurais. De acordo com esse diploma legal, as famílias têm o direito à assistência técnica pública e gratuita para a elaboração do projeto e a construção de habitação de interesse social para sua moradia. Essa assistência pode ser oferecida diretamente às famílias ou a cooperativas, associações de moradores ou outros grupos organizados que as representem.

Em 2009, como um dos eixos do Programa de Aceleração do Crescimento, o Governo Federal lançou o Programa Habitacional Minha Casa - Minha Vida (MCMV), por intermédio da Medida Provisória noㅡ

3 Disponível em: http://www.brasil.gov.br/pac/o-pac/ e http://www.planejamento.gov.br/secretarias. 
459, de 25 de março de 2009, transformada na Lei no 11.977, de 7 de julho de 2009 e alterada pela Lei 12.424, de 16 de junho de 2011. O fito principal do programa é diminuir o déficit habitacional no país, por intermédio de dois subprogramas: o Programa Nacional de Habitação Urbana (PNHU) e o Programa Nacional de Habitação Rural (PNHR). Esse déficit em 2010, de acordo com o Instituto Brasileiro de Geografia e Estatística (2010) e estudo realizado pela Fundação João Pinheiro (2013), era de 6.940.691 moradias. Desse total, 5.885 .528 (85\%) localizam-se no meio urbano e 1.055.163 (15\%) no meio rural. Objetivou, também, criar mecanismos de incentivo de produção e requalificação de imóveis urbanos e rurais para diminuir o déficit habitacional, em especial, da faixa da população de baixa renda. O Programa Minha Casa - Minha Vida se apresenta como o maior programa habitacional já lançado no Brasil.

Cabe destacar, ainda, a importante participação dos movimentos sociais no sentido de buscar soluções para minimizar a situação do déficit habitacional no campo. Neste sentido ressalta-se a participação do Movimento dos Pequenos Agricultores (MPA), que desde 1998 tem na pauta de suas reivindicações a criação de um programa para a habitação camponesa. Essa demanda foi apresentada tendo em vista a situação difícil que se encontravam os camponeses. Segundo o MPA (Comunicação MPA:<www.mpabrasil.org.br>), essa conjuntura ocorria,

\begin{abstract}
Devido às políticas neoliberais, o abandono das famílias no campo gerou um empobrecimento que se manifesta diretamente nas casas das famílias camponesas. Quando a casa esta ruim reflete diretamente na autoestima da família, na qualidade de vida, na permanência da juventude no campo. Portanto a habitação camponesa é uma política estratégica para conter o êxodo rural e melhorar a qualidade de vida das famílias no campo.
\end{abstract}

De acordo com o MPA, esse pleito que vem sendo realizado tem alcançado sucesso dentro dos objetivos do movimento, o qual seja buscar melhores condições de moradia para as famílias do campo. Ainda, conforme o MPA, até o ano de 2011, em nove
Estados brasileiros, 10.218 famílias camponesas construíram suas casas por intermédio do MPA (Cooperativa da Habitação Camponesa Ltda.). ${ }^{4}$ Desse total, 5.566 (54\%) famílias são do Rio Grande do Sul.

Nota-se, também, que ações governamentais mais efetivas, quanto ao equacionamento do déficit habitacional do rural, vêm sendo observadas com a implantação do Programa Minha Casa - Minha Vida, que tem como parte integrante o subprograma denominado Programa Nacional da Habitação Rural, implementado a partir de 2011.

No que concerne aos trabalhos relativos à habitação rural, verifica-se que ainda são escassos. De acordo com Abreu (2012), o tema é incipiente no meio acadêmico, tendo em vista que poucos trabalhos, relativos aos anos anteriores a 2006, foram encontrados. Nos últimos tempos o assunto passou a chamar a atenção dos pesquisadores. No período entre 2006 a 2012 foram elaborados cinco trabalhos versando sobre o tema habitação rural. Isso, conforme Abreu (2012) "[...] é um bom sinal do meio acadêmico em relação ao tema."

\section{Breve apresentação do programa nacional de habitação rural}

O Programa Nacional de Habitação Rural (PNHR) faz parte do Programa Minha Casa - Minha Vida. A gestão do programa está a cargo do Ministério das Cidades. O programa foi criado pelo Governo Federal para atender as necessidades habitacionais da população que vive no campo.

Tem como objetivo principal: "Produzir novas unidades habitacionais nas propriedades rurais, posses e em agrovilas, ou reformar as existentes." (BRASIL, CARTILHA DO PNRH, 2013, p. 1).

Os recursos para operacionalizar o programa originam-se do Orçamento Geral da União (OGU) e do FGTS. Os recursos do OGU são destinados aos subsídios e os do FGTS ao financiamento. Como

Fonte: CooperHab/MPA. Disponível em: $<w w w . m p a b r a s i l . o r g . b r>$. 
operadores financeiros do programa estão designados o Banco do Brasil e a Caixa Econômica Federal.

O acesso aos recursos do PNHR é realizado por intermédio de grupo de agricultores organizados pelas Entidades Organizadoras (EO). As EO são organizações públicas, prefeituras, governos estaduais e do distrito federal, e companhias de habitação, se houver, e as entidades privadas são àquelas sem fins lucrativos e representativas dos grupos associativos, tais como: sindicatos, associações, condomínios e cooperativas. Além da organização dos grupos, as EO têm, dentre outras, as seguintes atribuições: prestar assistências técnica e social, elaborar a documentação necessária para a contratação das operações, realizar levantamentos sobre as necessidades de moradias em sua área de atuação, coordenar as reuniões dos comitês gestores dos projetos, atestar o fim das obras, do trabalho social e da entrega das residências.

O público alvo do programa constitui-se de: "Agricultores familiares, trabalhadores rurais, assentados do Programa Nacional de Reforma Agrária - PNRA, quilombolas, extrativistas, pescadores artesanais, ribeirinhos, indígenas e demais comunidades tradicionais com renda mensal bruta anual até $\mathrm{R} \$ 60.000,00$, [...]."(BRASIL, CARTILHA DO PNRH, 2013, p. 1). Esse público está divido em três grupos, a saber: Grupo 1: famílias com renda bruta anual até $R \$ 15.000,00$; Grupo 2: famílias com renda bruta anual de $R \$ 15.000,01$ a $R \$$ 30.000,00; e Grupo 3: famílias com renda bruta anual de $R \$ 30.000,01$ a $R \$ 60.000,00$. O Grupo 1 recebe subsídio integral para construção ou reforma, o grupo 2 é atendido com recursos do Fundo de Garanta do Tempo de Serviço (FGTS) e recebe um desconto de $\mathrm{R} \$ 7.610,00$, e os recursos financeiros para o grupo 3 são oriundos também do FGTS.

Os valores dos subsídios destinam-se a cobrir os custos da construção ou da reforma da unidade habitacional, de assistência técnica e do trabalho social.

O PNRH prevê, ainda, o financiamento para a construção de cisternas para as famílias enquadradas no grupo 1, desde que residentes em áreas com dificuldade de acesso à água para o consumo humano.

\section{Habitação rural: um estudo preliminar sobre Santa Cruz do Sul, RS}

Santa Cruz do Sul localiza-se na área centro oriental do Rio Grande do Sul, na encosta inferior do nordeste do território estadual, e integra a região do Vale do Rio Pardo, da qual é considerado município polo (figura 1).

Figura 1 - Localização de Santa Cruz do Sul

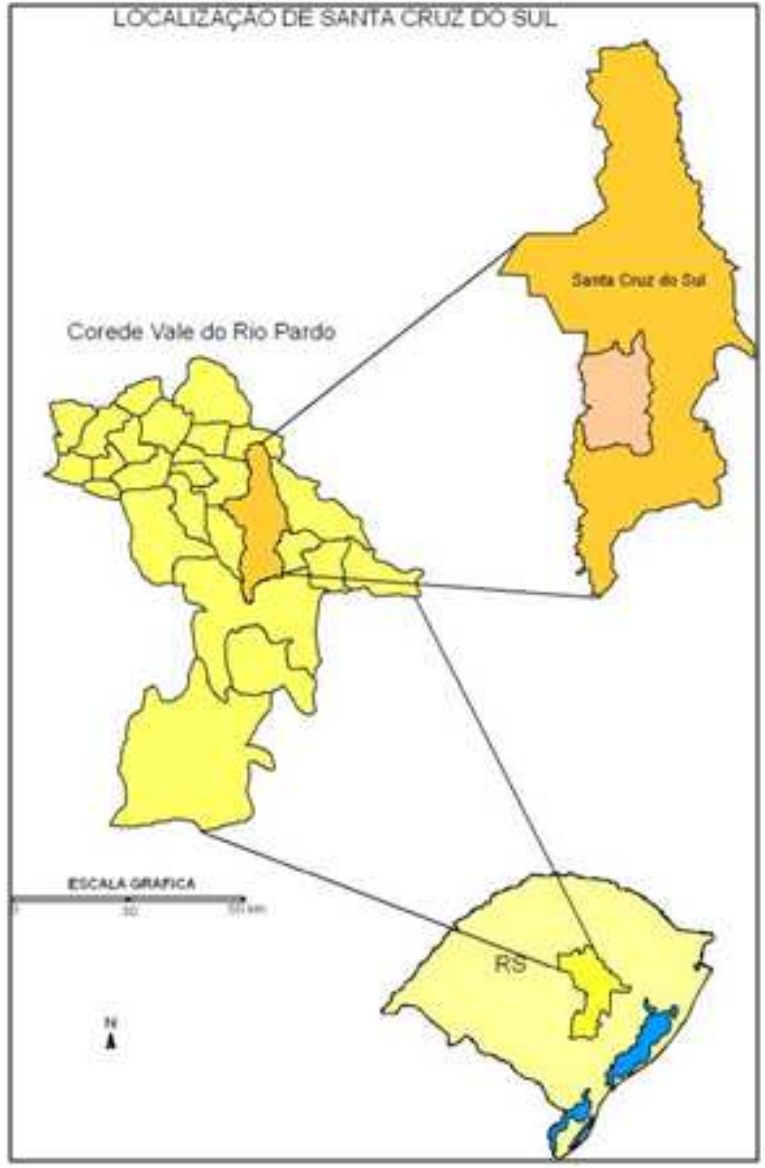

Fonte: Oliveira, 2010. Laboratório de Geoprocessamento UNISC.

Faz limites com os municípios de Venâncio Aires, Rio Pardo, Passo do Sobrado, Vera Cruz e Sinimbu. Encontra-se a $155 \mathrm{~km}$ da capital do Estado, Porto Alegre. A área total do município é de 794,49 $\mathrm{km}^{2}$, sendo 156,96 km² de área urbana e $637,53 \mathrm{~km}^{2}$ de área rural (PREFEITURA MUNICIPAL DE SANTA CRUZ DO SUL, 2010). 
Sua população total é de 118.287 habitantes, conforme o censo demográfico do IBGE (2010). Apresenta-se concentrada na sua área urbana com 105.184 habitantes e os residentes rurais totalizam 13.103 habitantes, o que the confere uma taxa de urbanização de 88,9\% e uma densidade demográfica de $161,4 \mathrm{hab} . / \mathrm{km}^{2}$.

O Produto Interno Bruto (PIB) do município, relativo ao ano de 2011, foi de $R \$ 4.943 .635 .000,00$ e o PIB per capita (2011) $\mathrm{R} \$$ atingiu 41.474,00 (FEE, 2012).

A economia do município encontra-se baseada na produção de tabaco e caracteriza-se pela existência de pequenas propriedades. Possui 4.365 propriedades rurais com a área média de 12,7 hectares ${ }^{5}$. Produz, ainda, os seguintes produtos agropecuários: milho, arroz, soja, feijão, mandioca, fruticultura, bovinos, aves, suínos e produção de leite.

Desde o início da colonização, a produção agropecuária do município, embora diversificada, já apresentava destaque na produção do tabaco. Nesse sentido, de acordo Silveira e Hermann (2001, p. 229), "A atividade fumicultora desde cedo representou 0 principal esteio da economia santa-cruzense, articulando a produção do fumo na zona rural e o beneficiamento industrial do fumo na cidade".

Para atender principalmente a indústria fumageira, o fluxo de trabalhadores vindos do meio rural do município e dos municípios vizinhos em busca de emprego aumentou consideravelmente a partir da década de 1970. Esse processo continuou intenso nas décadas posteriores. Conforme Silveira (2003), em 1980, a população urbana do município atingiu o percentual de 55,3\%, correspondendo a 55.096 mil habitantes. A população rural totalizou
44.541 mil residentes. Esse percentual alcançou 67,00\%, em 1991, e atingiu 87,10\% no ano 2000. Esse fluxo de pessoas, de acordo com Silveira (2003), instalou-se, principalmente, nos bairros próximos das indústrias. Em função do rápido crescimento populacional da área urbana, essas áreas não tinham habitações e infraestrutura adequadas.

A situação habitacional da área rural do município especialmente das famílias de baixa renda, não era diferente daquelas encontradas no meio urbano. Moradia precária e dificuldade de acesso aos poucos programas e projetos existentes, que possibilitem o equacionamento dessa situação. Nesse sentido Peres (2003, p. 81) afirma: "Além da falta de aplicação da legislação, são quase inexistentes as situações em que o trabalhador rural pode conseguir uma linha de financiamento para sua habitação."

Visando atender as famílias rurais do município, possibilitando-as alcançar melhores condições de moradia e qualidades de vida, a partir do início dos anos 2000, por intermédio de programas e projetos de financiamento habitacional foi possível a essas famílias a construção, reforma ou ampliação de suas casas. Nesse sentido, destaca-se a participação de entidades representativas de classe (Sindicato dos Trabalhadores Rurais) e de movimentos sociais (Movimento dos Pequenos Agricultores, por exemplo), na realização de ações na busca de equacionar esse grave problema.

No período de 2002 a 2013 foram construídas 289 (duzentas e oitenta e nove) unidades habitacionais no município de Santa Cruz do Sul, conforme a tabela abaixo.

Tabela - Santa Cruz do Sul - unidades habitacionais construídas

\begin{tabular}{l|l|l|l|l|l|l|l|l|l|l}
\hline Município & 2002 & 2003 & 2004 & 2005 & 2006 & 2008 & 2009 & 2012 & 2013 & Total \\
\hline Santa Cruz do Sul & 10 & 15 & 12 & 34 & 28 & 12 & 16 & 80 & 82 & 289 \\
\hline
\end{tabular}

Fonte: Sindicato dos Trabalhadores Rurais de Santa Cruz do Sul; Cooperativa da Habitação Camponesa Ltda. (CooperHab/MPA); e Jornal Gazeta do Sul.

\footnotetext{
${ }^{5}$ Fonte: Guia Socioeconômico do Vale do Rio Pardo e CentroSerra, 2013.
} 
No ano de 2002 foram construídas 10 casas no município, fruto de um projeto piloto. Tendo em vista a falta de destinação de recursos por parte do Governo Federal nos anos de 2007 e 2010 não foram realizadas construções. Já no ano de 2011 não houve construções.

Observa-se que a partir da criação do Programa Nacional da Habitação Rural, houve um aumento significativo na quantidade de casas construídas. Considerando somente os anos de 2012 e 2013, a quantidade de habitações edificadas equivale a $56 \%$ do total das unidades construídas até então. Salienta-se, também, o grande volume de recursos que circulou na economia do município no período. Segundo o Sindicato dos Trabalhadores Rurais e a CooperHab/MPA, a totalidade desses recursos ficou em torno de $\mathrm{R} \$ 8.200 .000,00$. Desse total, cerca de $R \$ 4.600 .000,00$ (quatro milhões e seiscentos mil reais) somente nos últimos dois anos (2012 e 2013). Ainda, de acordo com as Entidades Organizadoras, essas obras possibilitaram um excelente movimento no comércio de material de construção, bem como a geração de empregos e renda com a contratação de mão-de-obra de pedreiros, pintores, auxiliares de obra, dentre outros.

Com respeito aos objetivos do Programa, o Sr. Gerson Morsh, ${ }^{6}$ secretário do Sindicato dos Trabalhadores Rurais de Santa Cruz do Sul, afirmou que o mesmo vem atingindo plenamente o objetivo para o qual foi criado, ou seja, o de possibilitar às famílias do meio rural morar numa casa digna; "Objetivo principal está sendo atingido pelo fato das famílias estarem morando numa casa digna. Casa é o mínimo que o ser humano precisa para viver com dignidade."

Nesse sentido, pode ser verificado, que o objetivo do programa está sendo atingido, nas palavras do Sr. Glênio José e de sua esposa a Sra Helena Maria Sehn, que moravam com familiares, na localidade de Linha João Alves: "Agora podemos pensar em aumentar a família”, comenta Helena. [...]

\footnotetext{
6 Respostas ao questionário apresentado ao Secretário do Sindicato dos Trabalhadores Rurais de Santa Cruz do Sul, em 02 fev. 2014.
}

"Se não fosse o projeto, com certeza a gente demoraria mais para fazer a mudança."7

Da mesma maneira, declarou o Sr. Celso Valdir Theis, agricultor em Alto Paredão, que mora com a família em um chalé de mais de 20 anos. Essa habitação, segundo o agricultor, está em condições precárias e não oferece condições para a criação das crianças. "Com nosso novo lar, a vida vai mudar para melhor. Nossos filhos terão mais espaço para crescer e brincar."

O Sr. Gerson Morsh salienta, também, que a possibilidade de atender o homem do campo com uma habitação digna, tem sido uma importante estratégia para conter o êxodo rural. "A garantia de moradia é muito importante para as famílias do interior e ajuda a frear o êxodo. É comprovado que, com uma casa em boas condições, os jovens pensam duas vezes antes de migrar para as cidades."

A busca por melhores condições de moradia no campo é também uma estratégia que Movimento dos Pequenos Agricultores (MPA) vem buscando desde 1998. Conforme o Sr Caio Santana, da Cooperativa da Habitação Camponesa Ltda., "A habitação camponesa é uma política estratégica para conter o êxodo rural e melhorar a qualidade de vida das famílias no campo". ${ }^{10}$

Ainda, conforme o MPA, "Hoje, a habitação camponesa tornou-se um programa, o Programa Nacional de Habitação Rural - PNHR, que tem como meta construir 60.000 casas no campo. Entretanto o déficit habitacional no campo é enorme, e muito ainda tem por se fazer para garantir que toda família camponesa tenha uma moradia digna." (Comunicação MPA: <www.mpabrasil.org.br>).

Observa-se, também, que esse pleito que vem sendo realizado pelo Movimento dos Pequenos Agricultores tem alcançado sucesso dentro dos objetivos desse movimento social, o qual seja buscar melhores condições de moradia para as famílias do

\footnotetext{
7 Entrevista concedida ao Jornal Gazeta do Sul, edição de 28 ago. 2013.

8 Entrevista concedida ao Jornal Gazeta do Sul, edição de 06 jun. 2012.

${ }^{9}$ Fonte: Sindicato dos Trabalhadores Rurais de Santa Cruz do Sul.

${ }^{10}$ Fonte: Jornal Gazeta do Sul, edição de 05 jul. 2013.
} 
campo. Cabe salientar, ainda, que, em 2002, por intermédio de um projeto coordenado pelo MPA, foram construídas 2.032 casas para famílias camponesas, no Rio Grande do Sul. Esse projeto foi financiado na sua totalidade com recursos públicos. Conforme 0 MPA (Comunicação MPA: $<$ www.mpabrasil.org.br>), "Foi a primeira vez na história do país que se construíram casas com recurso público nas comunidades camponesas brasileiras."

Observa-se na figura 2 a situação da unidade habitacional de uma das famílias do interior do município, antes e depois de ser beneficiada pelo PNHR.

\section{Figura 2 - Santa Cruz do Sul - situação da unidade} habitacional

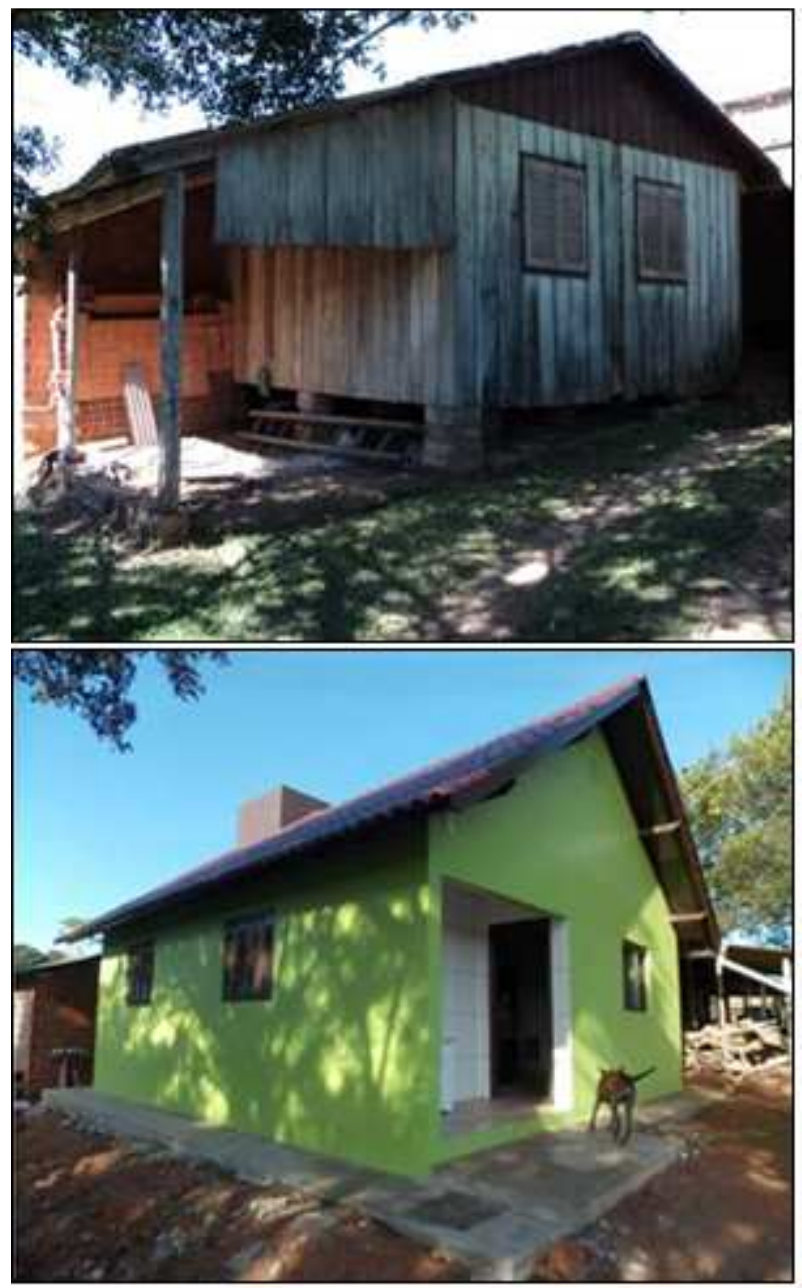

Fonte: Sindicato dos Trabalhadores Rurais de Santa Cruz do Sul, 2014.

No que concerne às parcerias para a realização dos projetos destacam-se a Empresa de
Assistência Técnica e Extensão Rural (Emater/RS), por parte do Estado, e a Prefeitura, no âmbito municipal.

O trabalho realizado pela Emater está relacionado às melhorias do entrono das unidades habitacionais e verificação das condições de moradia e, em caso de necessidade, realizar o encaminhamento do agricultor às EO. Nesse trabalho são realizadas orientações técnicas e cursos quanto à implantação de ajardinamento e de hortas.

Quanto à participação da prefeitura de Santa Cruz do Sul no processo, além de realizar o cadastramento dos interessados no Cadastro Único para o acesso aos programas sociais mantidos pelo Governo Federal, realiza como contrapartida os trabalhos de preparação do local onde será edificada a residência, tais como: terraplenagem, realização de aterros, preparação de locais para a colocação de fossas, melhoramentos no acesso, dentre outros.

\section{Considerações finais}

A política habitacional brasileira passou a ser mais efetiva a partir da criação do Sistema Financeiro da Habitação e do Banco Nacional da Habitação, em 1964, tendo em vista que a tentativa anterior, com a criação da Fundação da Casa Popular, não atingiu o objetivo desejado. Mesmo constando disposições legais no Sistema Financeiro da Habitação, o BNH não realizou ações efetivas quanto ao atendimento das necessidades habitacionais do meio rural. Com as dificuldades da economia brasileira, o BNH entra em crise e é extinto em 1986. Essa medida desarticulou e desestruturou ainda mais o SFH, situação que perdurou até meados década de 1990.

Com a estabilização da economia brasileira, alcançada com o Plano Real, novos órgãos e instrumentos voltados à política habitacional foram criados. Esses instrumentos tinham como objetivo principal equacionar os grandes problemas relativos às questões habitacionais herdadas de períodos anteriores. No entanto, as medidas foram mais voltadas para buscar o equacionamento da problemática habitacional no meio urbano. 
Com iniciativas de entidades representativas dos agricultores e de movimentos sociais têm sido possível, em Santa cruz do Sul, atender parte das necessidades em habitação na área rural do município. Salienta-se que a partir do início dos anos 2000, foram construídas 289 residências. Com a criação do PNHR, em 2011, que possibilitou a destinação de recursos para esse seguimento, a construção de moradias aumentou significativamente. Nos anos de 2012 e 2013 foram edificadas 162 casas, o que representa $56 \%$ do total de residências construídas no período de 2002 a 2013.

Observa-se, também, que os trabalhos relativos à habitação rural ainda são escassos. De acordo com Abreu (2012), o tema é incipiente no meio acadêmico, tendo em vista que poucos trabalhos, relativos aos anos anteriores a 2006, foram encontrados. Nos últimos tempos o assunto passou a chamar a atenção dos pesquisadores.

Assim, como parte do desenvolvimento rural na busca de uma melhor qualidade de vida do homem do campo, se faz necessário o aprofundamento do tema habitação rural por intermédio da realização de pesquisas e trabalhos futuros.

\section{Referências}

ABREU, M. G. de. Habitação de interesse social no Brasil: caracterização da produção acadêmica dos Programas de Pós-graduação de 2006 a 2010. Dissertação (mestrado) - Universidade Federal de Mato Grosso, Cuiabá, 2012. 154 p.

BRASIL. Cartilha do Programa Nacional de Habitação Rural (PNHR). Ministério das Cidades. Brasília, DF, 2013. Disponível em: http://www.cidades.gov.br. Acesso em: 21 jan. 2014.

BRASIL. Constituição da República Federativa do Brasil de1988. Brasília, DF: Senado Federal, 2013.

BRASIL. Lei no 4.380, de 21 de agosto de 1964. Diário Oficial da União (DOU), Brasília, DF: 1964.

BRASIL. Lei no 8.171, de 17 de janeiro de 1991. Diário Oficial da União (DOU), Brasília, DF: 1991.

BULGARELLI, Waldírio. As cooperativas e o Plano Nacional de Habitação. São Paulo: Livraria Pioneira Editora, 1966.
FUNDAÇÃO JOÃO PINHEIRO. Déficit habitacional municipal no Brasil. Fundação João Pinheiro. Centro de Estatística e Informações - Belo Horizonte, 2013.

FUNDAÇÃO DE ECONOMIA E ESTATÍSTICA. Resumo estatístico: municípios, Santa Cruz do Sul. Disponível em: <http://www.fee.tche.br>. Acesso em 10 fev. 2014

GREMAUD. A. P.; VASCONCELLOS, M. A. S. de.; TONETO JÚNIOR, R. Economia Brasileira Contemporânea. 7ª̣ Ed. São Paulo: Atlas, 2011.

JARDIM, Eduardo Maciel Ferreira. Dicionário Jurídico Tributário. São Paulo: Saraiva, 1995.

JORNAL GAZETA DO SUL. Edição de 23 julho de 2011. Santa Cruz do Sul.

JORNAL GAZETA DO SUL. Edição de 06 junho de 2012. Santa Cruz do Sul.

JORNAL GAZETA DO SUL. Edição de 05 de julho de 2013. Santa Cruz do Sul.

JORNAL GAZETA DO SUL. Edição de 03 de agosto de 2013. Santa Cruz Sul.

MARICATO, E. Política habitacional no regime militar: do milagre à crise econômica. Petrópolis: Vozes, 1987.

MOVIMENTO DOS PEQUENOS AGRICULTORES (MPA). Moradia Camponesa - Conquistas. Disponível em: <http://www.mpabrasil.org.br>. Acesso em 21/01/2014.

PERES, R. B. Habitação Rural: Discussão e diretrizes para políticas públicas, planejamentos e programas habitacionais. Dissertação de mestrado. USP, São Carlos, 2003. 212 p.

SANTA CRUZ DO SUL. Prefeitura Municipal de Santa Cruz do Sul: informações gerais. Disponível em: <http://www.santacruz.rs.gov.br/geo>. Acesso em 2013.

SANTOS, M. A urbanização brasileira. 2. ed. São Paulo: Hucitec, 1994.

SILVEIRA, R. L. L. da. Cidade, corporação e periferia urbana: acumulação de capital e segregação espacial na (re)produção do espaço urbano. Santa Cruz do Sul: EDUNISC, 2003.

SILVEIRA, R. L. L. da.; HERMANN, E. As Cidades e a urbanização do Vale do Rio Pardo. In: VOGT, O. P.; SILVEIRA, R. L. L. de (Org.). Vale do Rio Pardo: (re)conhecendo a região. Santa Cruz do Sul: EDUNISC, 2001.

SINDICATO DOS TRABALHADORES RURAIS DE SANTA CRUZ DO SUL. Santa Cruz do Sul, 2014. 
SINGER. Paul. A Crise do "Milagre": interpretação crítica da economia brasileira. 4를 Ed. Rio de Janeiro: Paz e Terra, 1977.

SOUZA, M. A. de A. Pensando a política nacional de habitação para adversidade das famílias e dos municípios brasileiros. In: BITOUN, Jan; MIRANDA, Lívia (Org.). Desenvolvimento e Cidades no Brasil: Contribuições para o Debate sobre as Políticas Territoriais. Recife: FASE: Observatório das Metrópoles, 2009. 